\title{
DIGITAL TECHNOLOGY IN PRESERVATION OF BUDDIST MONASTERY TREASURES
}

\author{
AShaftel $^{\text {a }}$ \\ a Treasure Caretaker Training, 6201 Shirley Street, Halifax, NS B3H 2N3 info@,annshaftel.com
}

KEY WORDS: Education, Digital Documentation, International Heritage Preservation, Earthquake, Risk Assessment, Buddhist Monastery, Preservation

\begin{abstract}
:
Treasure Caretaker Training (Digital Monastery Project), teaches Buddhist monks, nuns and community cultural caretakers to protect and preserve their own monastery sacred art treasures. Participants learn to create digital inventories by use of their own mobile phones. Included in this documentation is the video interview of elders who hold the oral history of many of the treasures. Risk assessment and disaster mitigation are taught.
\end{abstract}

\section{INTRODUCTION}

Treasure Caretaker Training (Digital Monastery Project), teaches Buddhist monks, nuns and community cultural caretakers to protect and preserve their own monastery sacred art treasures. We teach within a culturally conservative monastic structure where hierarchy and confidentiality are firm. The project itself is internationally recognized and won the prestigious Digital Empowerment Foundation Manthan Award, and ENorthEast award for innovative use of digital technology in cultural heritage preservation. The educational component of the project is worth discussing.

Participants learn to create digital inventories of their monastery treasures by use of their own mobile phones. Digital inventory is crucial, with the ever-present danger of art theft from monasteries, natural disasters and political upheaval: all threaten collections of sacred art in monasteries.

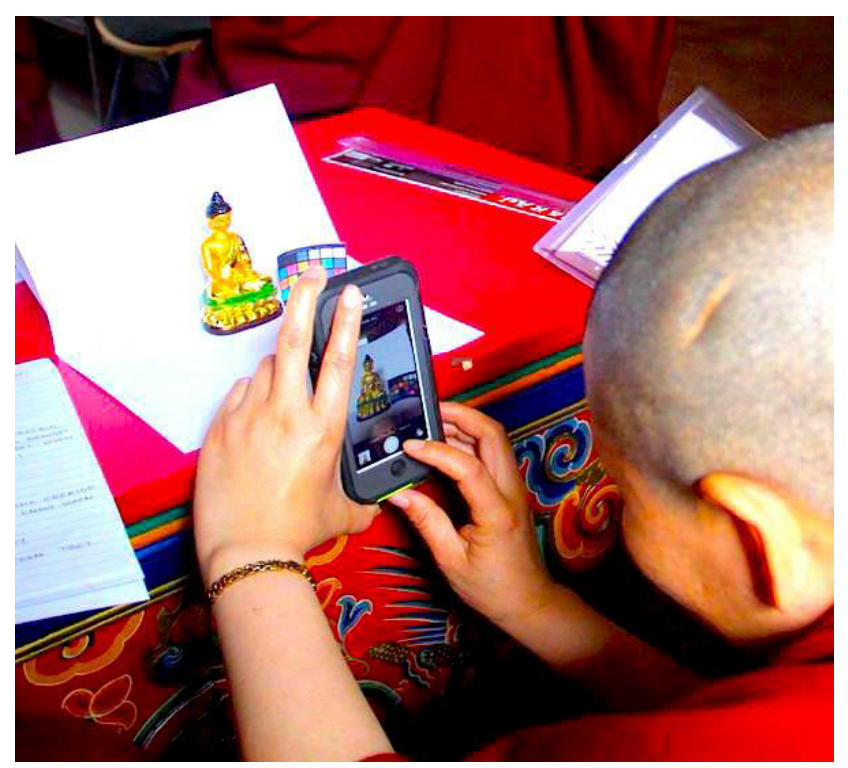

Figure 1. Nun learning digital documentation on her own mobile

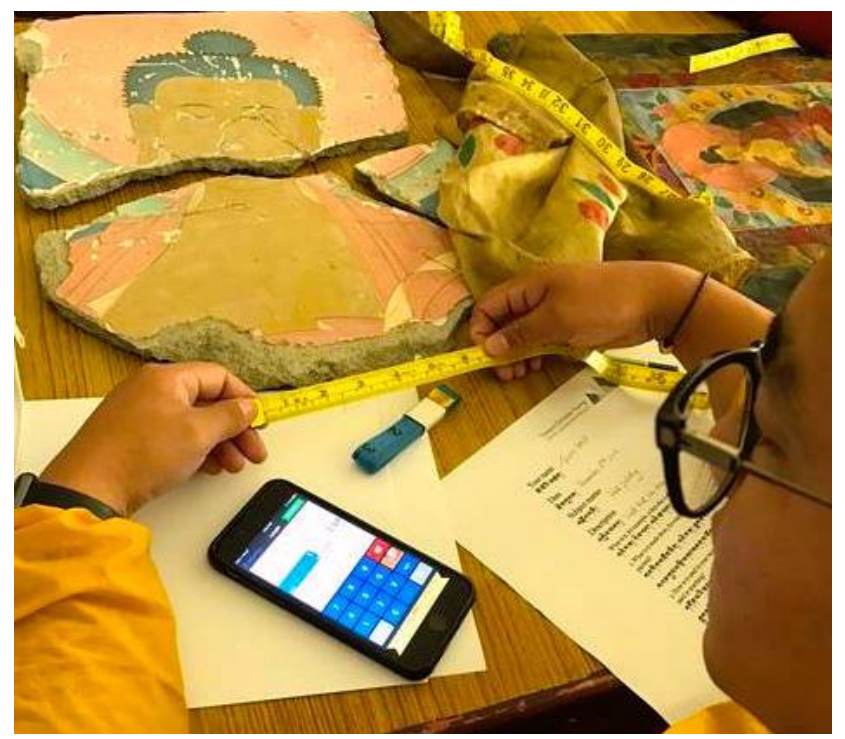

Figure 2. Monk in Nepal documents fragments of wall painting that he saved after earthquake destroyed his monastery temple

In remote Buddhist diaspora monasteries, monks and nuns own smartphone mobiles and tablets, but few own computers, and fewer would understand the complicated museum standards cataloguing programs that are designed to create digital inventories. Treasure Caretaker Training devised collections management documentation using the electronics that people own, and the techniques they already use and know.

Included in this documentation is the interview of elders who hold the oral history of many of the treasures. Treasure Caretaker Training teaches participants how to conduct an interview with an elder, how to capture it on their mobiles and how to add it to digital documentation files. 


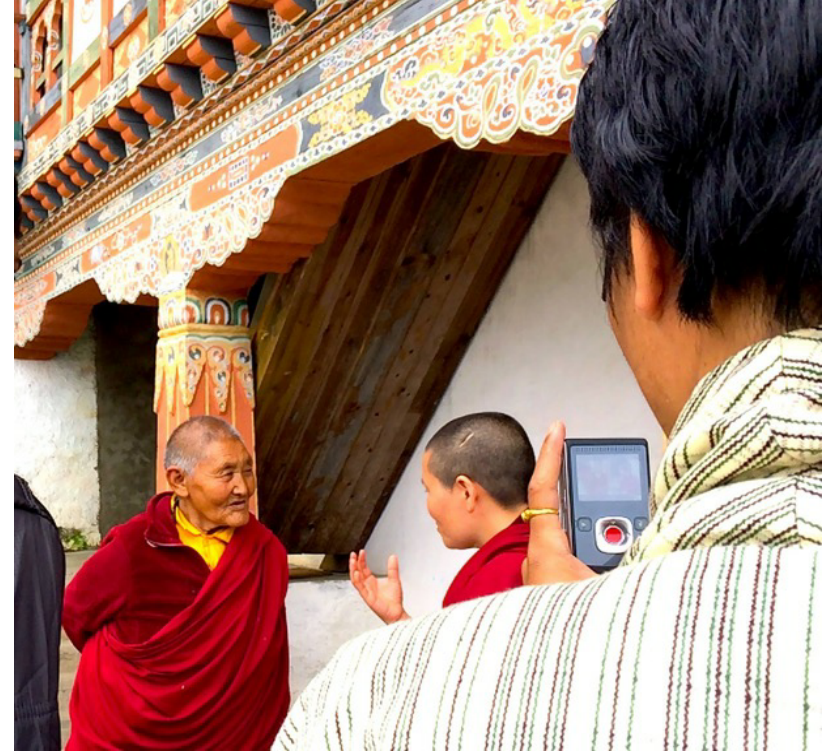

Figure 3. Video interview of monastery elder

Beginning in 2005, we introduced risk assessment for monasteries: following the Nepal earthquakes, risk assessment, emergency preparedness and disaster recovery are an increasingly important component of our monastery education sessions. Sikkim and Bhutan, as well as Nepal-in fact the entire Himalayan region and other sectors of the Buddhist diaspora-have frequent earthquake tremors with more intense quake events. We are working in a geographic area rife with earthquakes, fires, and yearly monsoon.

Treasure Caretaker Training workshops include training in:

- Documentation, Written and Digital, including description and photography

- Documentary Interviews of Monastery Elders

- Preservation of dPechas (traditional texts)

- Preservation of Thangkas

- Preservation of Buddhist Wall Paintings

- Preservation of Monastery Treasures through Display and Storage

- Risk Assessment and Emergency Preparedness for Preservation of Monastery Treasures

Preservation of Monastery Treasures workshops evolved from the author's work with Buddhist sacred treasures in monasteries since 1970. Previous work included monasteries and museums in India, China, Nepal, Bhutan, North America and Europe. With graduate degrees in Art Conservation and History of Art, the author also advises for, does conservation treatments, lectures and teaches in museums and for universities internationally. Preservation clients include: Art Institute of Chicago, Asian Art Museum of San Francisco, American Museum of Natural History, Rubin Museum of Art, Royal Ontario Museum, Canadian Department of National Defence, National Museum of India, Library of Tibetan Works and Archives, Namgyal Institute of Tibetology, Yale Beinecke Library and others. The author also advises for, does conservation treatments, lectures and teaches for Buddhist groups of all lineages, and other churches.

The approach of science-based art conservation remains the same, whether working and teaching in a major museum, or in a remote monastery in the Himalayas. Adjustments are made in presentation and wording, with respect for cultural differences and religious and cultural traditions. Forty-four years of working with monasteries and museums as conservator preceded the first training session under the Treasure Caretaker Training umbrella, including seminars and workshops in India and Bhutan.

The first official implementation under the Treasure Caretaker Training registered charity was in Sikkim, May 2014. Fifty monks, nuns, archivists, museum caretakers and army security personnel joined in the training. Workshops followed in Bhutan (with UNESCO and the Royal Government of Bhutan), in Sikkim (with the Government of India), in Bodhgaya (Kagyu Monlam), in Nepal (monastery advisory tour, and workshop at Tergar Oselling), and for the Library of Tibetan Works and Archives in Dharamshala.

Recently, following invitations by conservators in the USA, work in New York City included a workshop in conservation of thangkas (Buddhist scroll paintings) held at TALAS, lectures at the Rubin Museum and Jacques Marchais Museum of Tibetan Art, and private thangka collection tours, to study storage and display techniques.

Schedules of Treasure Caretaker Training sessions differ according to venue and participant demographics. Once, the author taught a Thangka Conservation workshop in Bhutan for four and a half months, seven days a week. However, the current format of Treasure Caretaker Training can range from three days, to twelve days. All sessions follow a successful and similar format of illustrated lectures, practical assignments, group discussions, and field trips, with receptions in the beginning and the end.

The classroom is set up with movable tables and chairs that are arranged for lectures in the morning, and for team hands-on work in the afternoons. The classroom walls are decorated with posters of scientific analysis of Buddhist art, posters from international conservation organizations, and walls with posters ready for risk assessment tabletop group learning. Treasure Caretaker Training provides the artifacts for documentation practice, including statues, texts, thangkas, brocade temple chevrons, etc.

The mornings consist of Keynote or PowerPoint lectures with time for discussion and Q\&A. The afternoons consist of handson learning with actual practice in documentation of treasures, for risk assessment table-top exercises, and/or field trips to neighboring monasteries and museums to practice new skills. Every afternoon session is followed by a presentation by the teams on their work, for example their documentations, or their risk assessment findings for a site we visited. Reports are projected and team members gain practice in presents and lecturing to others. A fresh Keynote or PowerPoint is compiled by the instructor from the documentation or site visit reports and images from the participants' own mobiles. 


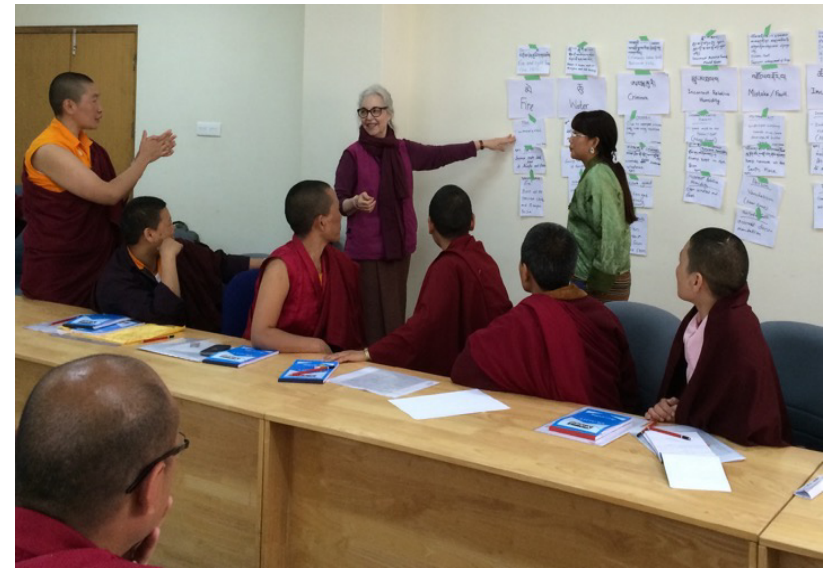

Figure 4. Risk Assessment group discussion

Afternoon sessions are the most interesting for the participants as they enjoy working in teams. Monasteries are by nature team oriented and friendly to group effort and friendly competition. Presentation in front of the entire group creates the ability to transfer knowledge learned to home monasteries or communities when the workshop has concluded.

Culturally, we are working in a Buddhist cultural/religious diaspora that crosses geographic boundaries and is experiencing rapid cultural change. For example, images and information that the author presented in 2005 would be outdated for participants, who now have access to the internet.

Some monasteries experience tension between India and China in general, and in the border areas where specific monasteries are located. Bhutan, Sikkim and Nepal are each considered areas surrounded by political tension.

Within international Christianity, there are denominations of Catholics, Protestants, Baptists, Unitarians, Quakers and other groups with vastly differing belief systems and services. The international Buddhist diaspora also includes a range of texts, religious practices and ethical beliefs. Within the Tibetan Buddhist diaspora, there are distinct affiliations; for example, towards teachers and lineages.

Educational projects are notoriously difficult to fund. In the end, the funder can have little to show for a donation, except a report with images. Treasure Caretaker Training is a registered charity in the USA, a 501 (c) 3 entity. Our work has been funded by private foundations and individual donors, with in-kind and financial contributions from governments, universities, monasteries and UNESCO.

Translation is required for technical information, whether spoken or written. All of the documents, therefore, are translated into the language of the spoken translation. So far, that has been either Tibetan or Nepali. Many people speak English and in one session our translator was a senior monk, fluent in English, Tibetan, Nepali and Hindi, and a fine translator. The apps we are developing for mobile phones will also be translated, funding permitting, into Tibetan, Nepali, Chinese, Hindi and Dzongka.

The teaching teams have varied in size and background according to the request of the monastery or museum, and according to topic or funding. For example, one governmentfunded twelve-day workshop requested that the author teach it alone, working with their professional staff for logistical support, translation and professional assistance.

At a previous session, several North American conservators wanted to come to assist, but they were not asked to return by the organizers. Few professionals would like to work for free, and/or pay their own travel expenses, since funding is sparse for educational sessions. However other issues have come up: lack of experience in monastery manners and culture, too scientific or technical for participants to relate to, or, simply not Buddhist. This last may seem not relevant, but in the conservative world of monasteries, where confidentiality is of utmost importance, it is important that someone invited inside is well known and already well trusted. In fact, one venue asked for Buddhist teachers only.

The class compositions have varied to a point, that colleagues who work as professional educators have shown true dismay at the range of people contained in any given group. The project began in 1970 with the author alone working in a monastery with two or three monks only. These monks were the current Kunyers, or caretakers, of the monastery treasures. The author would return many times to the same monastery and often the Kunyers would have changed, according to their rota assignment. There was little mechanism/structure for the transference of information about monastery treasures during the exchange of positions. Previously, oral transmission might have insured this transfer of information. Since written documentation was rare, the oral transmission was crucial. The current group of Kunyer are the fastest learners since we are teaching preservation of monastery treasures via use of their own mobiles.

In 2005, the author worked in Bhutan, training monks, nuns and cultural officers. Even within that group there was a range of age and educational background of participants. For example, monastics who enter early, receive religious training and are often well educated in dharma texts, but not in, for example, science.

In one group the monasteries were asked to send several monks each. One monastery sent ten-year olds. An art school sent teenage art students. Also, included in the group demographics were senior monks with heavy administrative responsibility, some of whom had grown up in the monastery. Others had gone through the equivalent of grade 12 in secular school. Also in the same group were accomplished and highly educated archivists and museum staff.

Another participant group consisted of government security personnel, archivists, and monks and nuns. In this group, the afternoon teams consisted of nuns together, as they requested. In other sessions, the nuns requested to be in mixed groups with monks and other participants. Some participant groups are restricted to monks only, and some are nuns only.

Developing future teachers from the groups make Treasure Caretaker Training sustainable. Natural leaders always arise within groups; however, all participants are expected to bring preservation information home following the session. Gender roles are more clearly defined within the Himalayan monastic communities and nuns are respected for and encouraged to be modest and discrete, so they were not accustomed to taking an active role in discussion with monks, addressing a group, or giving a presentation. This is slowly changing, and the situation varies. 


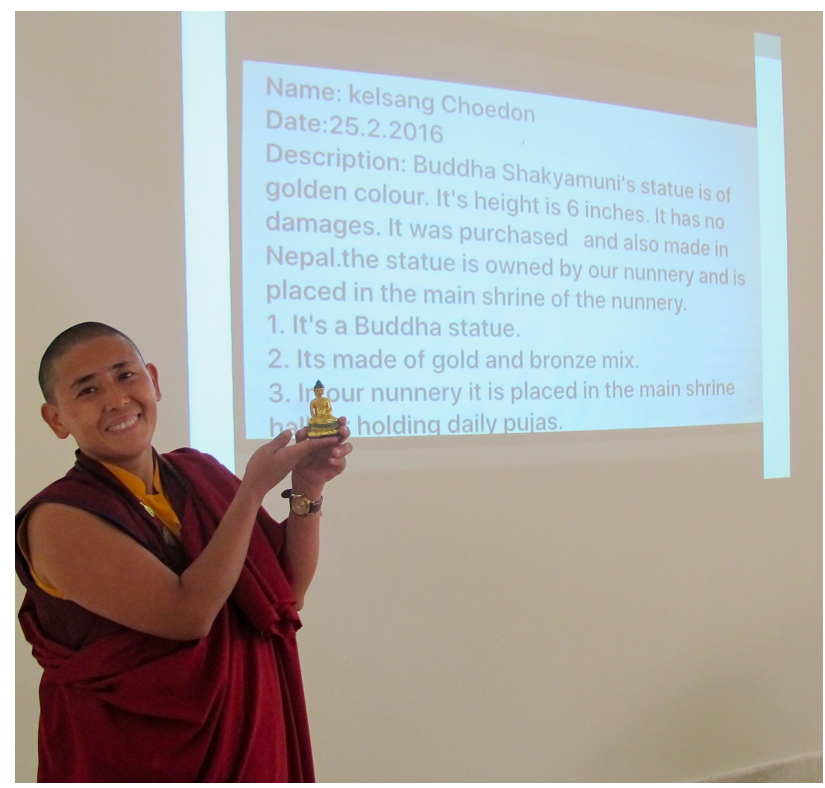

Figure 5. Participants train to share preservation skills in their home monasteries

Even within a homogenous group of participants, there are differing degrees of interest, commitment and suitability. This is especially true with science-heavy topics, such as risk assessment. And certainly, some people are born to work well with their hands, while other excel at different skills.

\section{CONCLUSION}

Our participants are currently waiting for easy access to preservation information relevant to their monastic and community life, in the form of Manual for Preservation of Monastery Treasures, our soon-to-be-published preservation manual created specifically for monasteries. The Manual is awaiting formatting for mobiles and tablets, and apps for digital documentation and risk assessment. Treasure Caretaker Training (Digital Monastery Project) preservation workshops and seminars for monks, nuns and community cultural caretakers continue, and continue to update, as digital technology and local conditions change.

\section{AUTHOR BIOS}

Ann Shaftel, MA, MSc Fellow International Institute for Conservation, Fellow American Institute for Conservation, Canadian Association of Professional Conservators, ICOMCanada, ICOMOS-Canada

\section{ACKNOWLEDGEMENTS}

Ven. Chogyam Trungpa Rinpoche, Karmapa Foundation, Khyentse Foundation, Shambhala Trust, Ani Pema Chodron Foundation, Yongey Foundation, Anne Thomas Donaghy, Jon Domagala, Jay Heisler, Claire Heisler, Erica Allanach, Rochelle Weithorn and numerous colleagues. 